\title{
Grammatikalisering af type-konstruktioner og pseudo-partitiver i dansk
}

\section{Henrik Høeg Müller, Kasper Boye \& Elisabeth Agerbo Mørch}

\begin{abstract}
The aim of this paper is to argue that Danish type-noun binominals (en slags cykel 'a kind of bike') and pseudo-partitive binominals (et stykke ost 'a piece of cheese') with the formal structure [N1 + N2] have followed analogical patterns of grammaticalization both structurally and functionally. On the basis of a study of 2946 tokens of slags 'kind' in the construction EN/ET-slags-S(noun), retrieved from KorpusDK, we discuss agreement features and polysemy in relation to the fact that slags occurs more frequently as a modifier marking 'association' than with its original taxonomic meaning. Against this background, we suggest that ultimately N2 is winning the competition for discourse prominence over slags, which, thus, is in the process of converting from a lexical to a grammatical element.
\end{abstract}

\section{Nøgleord}

diskursprominens, grammatikalisering, pseudo-partitiver, strukturel parallelisme, type-konstruktioner

\section{Indledning}

Ved at undersøge de syntaktiske og semantiske korrelationer mellem danske såkaldte type-konstruktioner (en slags cykel) og pseudo-partitiver (et stykke ost), begge med den formelle struktur [N1 + N2], vil vi forsøge at underbygge følgende to hovedpåstande: (1) at udviklingen af disse to konstruktionstyper fra henholdsvis "rigtige" partitiver (herefter bare partitiver) og "fulde" tak- 
sonomiske udtryk udviser en række strukturelle og funktionelle fællestræk, og (2) at type-konstruktioner og pseudo-partitiver således følger identiske grammatikaliseringsmønstre (jf. fx Masinis 2016 begreb om metakonstruktioner): N1 kan i begge tilfælde siges over tid til en vis grad at have mistet sin leksikalske status og være blevet et diskursivt sekundært element, dvs. en grammatisk markør, ift. andre primære elementer (Boye \& Harder 2012: 2).

Ud over analysen af de strukturelle ligheder mellem type-konstruktioner og pseudo-partitiver bygger vores antagelser om grammatikalisering inden for det taksonomiske område på en korpusundersøgelse af slags og andre type-ord i dansk samt deres betydningsændring og grammatikalisering (se Mørch 2017). Kort fortalt består korpusundersøgelsen i en semantisk og grammatisk klassificering af 2946 forekomster af slags og 150 forekomster af hver af type-ordene art, form for og type. Type-ordene er blevet ekstraheret fra KorpusDK på baggrund af flg. formaliserede konstruktionsmønster: ${ }^{1}$

\section{EN/ET $+(\mathrm{x}+)$ TYPE-ORD $+(\mathrm{x}+)$ SUBSTANTIV}

hvor $\left(\mathrm{x}^{+}\right)$angiver muligheden for, at ét eller flere andre ord forekommer mellem artiklen og type-ordet og mellem type-ordet og substantivet.

I kombination med de strukturelle analyser fungerer korpusundersøgelsen som udgangspunkt for en samlet vurdering af de danske type-ords grammatikaliseringsgrad - med særligt fokus på slags - ud fra den betragtning, at grammatikalisering kan defineres på følgende måde: "Grammaticalization is the diachronic change that gives rise to linguistic expressions that are conventionally ancillary and as such discursively secondary" (Boye \& Harder 2012: 7). Indsigten vedr. diskursprominens, dvs. konkurrencen mellem leksikalske elementer, er vigtig, og et lidt længere citat fra Boye \& Harders oversigtsartikel fra 2009 afgrænser præcist dette punkt.

"Grammatikalisering af et leksikalsk element består således i forandringen af et potentielt primært element til et inhærent sekundært, og en sådan forandring må være betinget af, at den leksikalske grammatikalseringskandidat optræder sammen med et andet leksikalsk

1 Det KorpusDK, der er anvendt her, er en nyere variant end det, der ligger online tilgængeligt på ordnet.dk. DSL har opdateret KorpusDK med et Korpus2010, således at det samlede korpus nu strækker sig fra ca. 1985-2010. Den nye version af KorpusDK er endnu ikke tilgængeligt for onlinesøgninger, men det er stadig et frit tilgængeligt korpus, som man kan få afgang til via hjemmesiden korpus.dsl.dk. 
element, i forhold til hvilket den i faktisk kommunikation kan være sekundær. Det er m.a.o. en betingelse for grammatikalisering af leksikalske elementer, at der er en strukturel mulighed for konkurrence om opmærksomhed, om diskursprominens." (Boye \& Harder 2009: 69).

Herudover er det afgørende, at det element, der kandiderer til grammatikalisering, oftere forekommer med sekundær end med primær status: "It must be used with a high frequency with secondary status relative to its uses with primary status" (Boye \& Harder 2012: 27), og at det skal være generelt anvendeligt i sin grammatikaliserede funktion (ibid: 73) (se også Boye \& Harder 2014: 11-13).

Som vi skal se i den følgende analyse, er det netop de forhold, at N1 strukturelt får status af klassifikator ift. N2, med deraf diskursiv nedgradering til følge, og at dette hyppigt og systematisk afstedkommer betydningsændring, der gør, at man med rimelighed kan diskutere visse type-konstruktioners grad af grammatikalisering.

\section{Strukturelle fællestræk mellem pseudo-partitiver og type-konstruktioner}

Nedenfor gennemgås en række strukturelle træk i form af præpositionsbrug, brug af bestemt artikel, anaforisk reference etc., som pseudo-partitiver og type-konstruktioner har mere eller mindre tilfælles.

\subsection{Partitiver vs. pseudo-partitiver}

Pseudo-partitiver kan defineres som udtryk for meronymi, der med N1 kvantificerer over en ikke nærmere identificeret mængde af den substans eller masse, N2 denoterer, som i (1). I modsætning hertil specificerer partitive konstruktioner med N1 en del af en given helhed, der udtrykkes af N2. Dvs. at N2 i partitive konstruktioner refererer til en specifik entitet, som i (2), i modsætning til hvad der gælder for pseudo-partitive konstruktioner (se fx Koptjevskaja-Tamm 2001, 2006, 2009 og Luraghi \& Huumo 2014). Det indebærer, at N2 i pseudo-partitiver altid er et masseudtryk eller et nøgent substantiv i pluralis, mens N2 i partitiver er et determineret NP.

(1a) et stykke ost
(1b) en skive brød 
(2a) et stykke af osten

(2b) en skive af brødet

\subsubsection{Korrelationer mellem brugen af preposition og determination $i \mathcal{N} 2$}

Eksemplerne i (3) og (4) viser en sammenhæng mellem anvendelsen af præposition og determination. Det vigtige her er, at brugen af præposition synes at korrelere med determination i den forstand, at tilstedeværelsen af af muliggør determination af $\mathrm{N} 2$, hvorimod sammenstilling af nominalerne kræver, at N2 er ubestemt, jf. kontrasten mellem (3a) og (3b) på den ene side, og (4a) og (4b) på den anden side (se også fx Climent 2001, Brems 2003, Keizer 2007 og Mirto \& Necker 2007 vedr. pseudo-partitivers struktur i en række andre sprog).
(3a) en skive af brødet
(3b) en sæk af det mel
(4a) *en skive brødet
(4b) *en sæk det mel

\subsubsection{Determination $i \mathcal{N 1}$}

Desuden kan N1 i pseudo-partitiver ikke forekomme med den bestemte artikel, mens det jo ikke er noget problem ved strukturer med præposition, jf. (5) og (6).

(5) skiverne af brødet

(6) *skiverne brød

\subsubsection{Adjektiomodifikation og anaforisk reference}

Når man kigger på, hvilke forhold der gør sig gældende ved adjektivmodifikation og anaforisk reference i forbindelse med henholdsvis pseudopartitiver og partitiver, er det vigtigt først og fremmest at skelne mellem konstruktioner, hvor N1 og N2 er korreferentielle, og konstruktioner, hvor de ikke er. Det sidste er typisk tilfældet, når N1 betegner en beholder af en art. Sondringen er relevant her, for i tilfælde af korreferentialitet mellem N1 og N2 vil de test, vi foreslår i (7) og (8) nedenfor, ikke kunne anvendes. Ifølge Daugaard (1994) kan sondringen vedr. korreferentialitet beskrives som nedenfor, hvor N1 betegnes som specifikator, N2 som artsled og hele konstruktionen som mængdehelheden. 
"Specifikatorer, der betegner en beholder, kan ikke være antecedent, og det er så enten artsleddet eller mængdehelheden, der er antecedent.:

Han landede en båd sild. *Den [dvs. båden] var af egetræ.

De [dvs. sildene] var fede.

Den [dvs. den båd sild] indbragte 1.000 kr."

Hvor specifikatoren er koreferentiel med artsleddet - herunder også specifikatorer der betegner en kvalitet - kan både mængdehelheden, artsleddet og specifikatoren være antecedent. I sidstnævnte tilfælde er specifikatoren at betragte som en ellipse for mængdehelheden.

Mureren købte to læs sand. De [dvs. de to læs (sand)] fyldte hullet. Det [dvs. sandet] var groft".

(Daugaard 1994: 52)

Det næste citat fra Stickney har vi taget med for at vise, at der, i hvert fald for så vidt angår engelsk, er en forskel på, hvad det foranstillede adjektiv modificerer, når det drejer sig om partitiver over for pseudo-partitiver. Ved pseudo-partitiver modificerer adjektivet hele mængdehelheden, mens determinationen blokerer for modifikation af N2 i forbindelse med partitiver. Bemærk, at denne forskel kun gør sig gældende, når N1 og N2 ikke er korreferentielle i henhold til Daugaards beskrivelse.

"An adjective preceding the pseudopartitive can modify the head (N2), 'chocolates' (7). An adjective modifying the partitive is blocked from doing so (8).

(7) a moldy box of chocolates

(8) a moldy box of those chocolates" (Stickney 2007: 407)

Noget tilsvarende gør sig formentlig gældende for danske oversættelser af Stickneys eksempler, men i (7) har vi valgt at illustrere det på en lidt anden måde.

(7a) fire rustne/rådne dåser rejer

(7b) en tør tube kaviar

(7c) ?en tør tube af den gode svenske kaviar 
(7a) viser, at når mængdehelheden har status af pseudo-partitiv, kan et foranstillet adjektiv modificere enten N1 eller N2 afhængigt af dets semantik. Derimod ser et adjektiv i samme position i forbindelse med en rigtig partitiv konstruktion (7) ud til at være blokeret fra at modificere N2. Med andre ord forekommer eksempel (7c) at være mere tvivlsomt semantisk set - selv om man naturligvis godt kan regne ud, hvad der menes - fordi tor formodes at skulle modificere kaviar og ikke tube. I overensstemmelse med Stickney (2007) kan vi sige, at determination af N2 i partitiven skaber en barriere for adjektivmodificering af N2, dvs. at adjektivet kun kan modificere N1 og derfor skal være semantisk kompatibelt med det nominal.

(8) nedenfor illustrerer forskellen mellem de to typer partitive strukturer ift. anaforisk reference. I (8a) - hvor der jo jf. Daugaards (1994) definition ikke er korreferentialitet mellem N1 og N2 - illustrerer indekserne, at det er muligt at vise tilbage til både N1, specifikatoren dåse (evt. opfattet som hele mængdeudtrykket, jf. Daugaard), og N2, artsleddet rejer. I modsætning hertil fungerer nominalerne i (8b), i hvert fald i højere grad, som separate enheder, og det synes derfor mindre naturligt at etablere anaforisk henvisning til specifikatoren alene.

(8a) Vi købte en dåse rejer $_{j}$ i går. De Den $_{\mathrm{j}}$, smagte pragtfuldt.

(8b) Vi købte en dåse ${ }_{i}$ af de friske, håndpillede rejer ${ }_{j}$ i går. $\mathrm{De}_{\mathrm{j}} /$ ? /*den $\mathrm{i}_{\mathrm{i}}$ smagte pragtfuldt.

Eksemplerne viser, at pseudo-partitiver i højere grad end partitiver optræder som en enhed i modsætning til to separate nominale elementer. Det gør de også prosodisk, så vidt vi kan se: Pseudo-partitiver har enhedstryk, hovedtryk på N1 og bitryk på N2, mens både N1 og N2 i partitiver har hoved-/fuldtryk. Følgende korte citat fra Stickney (ibid.) bekræfter netop antagelsen om en strukturel forskel på de to slags partitive strukturer: "The DP in the partitive creates a barrier to the adjectival modification of N2."

\section{2. "Fulde" taksonomiske strukturer vs. binominale type-konstruktioner}

I stedet for at udpege en mængde eller en del af N2 specificerer N1 i forbindelse med taksonomiske strukturer, at N2 kan klassificeres som tilhørende en bestemt type, som fx i (10). 
(9) en type af den multiresistente stafylokokbakterie MRSA

(10) Nogle islandske heste går også i "grisse-pas" som er en slags [type (af)] pas som er langsommere og mere uren (...) $(\mathrm{B} 1: 1197)^{2}$

I første omgang fokuserer vi udelukkende på type-ordene type og slags, da de ift. flere strukturelle og funktionelle parametre repræsenterer forskellige slags type-ord og til en vis grad konstituerer to yderpunkter ift. grammatikalisering, som vi skal se senere.

Mængden af danske substantiver, der betegner en taksonomisk kategori, er naturligvis større end de to type-ord type og slags og inkluderer - ud over type-ordene art og form for, der som nævnt også behandles i korpusundersøgelsen - type-ord som sort, klasse, kategori og gruppe.

Også inden for det såkaldte taksonomiske område kan vi skelne mellem fulde taksonomiske konstruktioner, der svarer til partitiverne, og en binominal type-konstruktion, der svarer til pseudo-partitiverne. Denne sondring illustreres med eksemplerne i (9) og (10) ovenfor. I (9) udgøres N2 af det bestemte nominal den multiresistente stafylokokbakterie MRSA, mens N2 i (10) består af det non-referentielle pas (plus relativsætning).

\subsubsection{Prepositionsbrug}

Type-konstruktioner og pseudo-partitiver deler den konstruktive egenskab at være i stand til - eller ligefrem være tvunget til, for så vidt angår slags - at optræde uden præposition, hvilket ellers er obligatorisk i forbindelse med de fleste andre typer binominale strukturer. Type-konstruktionerne $\mathrm{i}$ (10) peger på det faktum, at type kan konstrueres både med og uden præposition, mens slags kun forekommer uden, jf. deres forskellige status ift. grammatikalisering, som vi henviste til tidligere.

\subsubsection{Korrelationer mellem brugen af preposition og determination af $\mathcal{N} 2$}

Parallelt med sondringen mellem pseudo-partitiver og partitiver er der også en sammenhæng mellem brugen af præposition og determination af N2 inden for de taksonomiske konstruktioner. Ligesom inden for det partitive område kræver determination af N2 tilstedeværelse af en præposition ved type-konstruktioner, jf. (1 1a) i modsætning til (11b).

2 Angivelsen i den sidste parentes refererer til bilagsbindet i medforfatter Elisabeth Agerbo Mørchs kandidatspeciale. Bilagene indeholder alle de eksempler, der indgår i den førnævnte korpusundersøgelse, og de er alle blevet opmærket og underkastet betydningsanalyse. Den firkantede parentes i selve eksemplet indikerer, at type af ikke udgør en del af det originale eksempel, mens den runde parentes om af markerer, at præpositionen kan udelades. 
(11a) en type af det brød // en type af bilerne

(11b) *en type det brød // *en type bilerne

\subsubsection{Determination i N1}

Analogien med pseudo-partitiver og partitiver strækker sig også til spørgsmålet om determination af $\mathrm{N} 1$, hvilket betyder, at N1 ikke kan være i bestemt form, når type-konstruktionen forekommer uden præposition. Det er kun muligt med bestemt form af N1, når N1 og N2 er forbundet via en præposition, som vi kan se i (12a) og (12b).
(12a) typen af brød
(12b) *typen brød

Type-ordet slags kan godt optræde i bestemt form som i en anden type konstruktion end den, vi undersøger her, jf. (13).

(13) Allerede i starten af året kommer vi formentlig til at se en ny iPhone i butikkerne. Endda en billigere af slagsen.

https://www.altomdata.dk/billig-iphone-ude-om-et-par-maaneder/

\subsubsection{Numerus $i \mathcal{N} 2$}

Det konstruerede eksempel i (14) og de autentiske i (15) viser, at der ikke nødvendigvis er nogen talmæssig overensstemmelse mellem N1 og N2.

(14) De har opfundet en ny slags/type (af) batteri/batterier.

(15a) Takket være den lave vægt kan vognen trækkes af praktisk talt alle $t y$ per bil. https://www.camping-specialisten.dk/vognliste/autocampere/Tomplan-Silverline-- Mini-750--500-kg-66963?p=66963

(15b) Så derfor køber vi alle typer af bil, små som store biler. https://www.cph-bilhuset.dk/

Som vi kan se, følger numerus i N1 og N2 ikke hinanden for enhver pris - tilsyneladende også uafhængigt af, om type optræder med eller uden præposition - hvilket gør, at man kan antage en vis form for uafhængighed mellem de to nominale elementer. Det skal i denne forbindelse bemærkes, at slags ikke har en selvstændig pluralisform, og at det samtidig ser ud til, dog uden at dette punkt udgør en del af korpusundersøgelsen, at slags i pluralis ikke accepterer N2 i ental som i *Hun har kort i flere forskellige slags bil de senere år. 


\subsubsection{Anaforisk reference}

Hvad angår anaforisk reference må man i lyset af definitionen i afsnit 2.1.3. forvente, at når der er korreferentialitet mellem N1 og N2, kan både specifikator og artsled fungere som antecedent.

(16a) De har opfundet en ny slags/type ${ }_{i}$ (af) batteri. Det Deden $_{j}$ er meget $\operatorname{kraftfuld}\left(\mathrm{t}_{\mathrm{j}}\right)$.

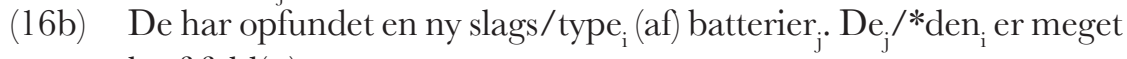
$\operatorname{kraftfuld}\left(\mathrm{e}_{\mathrm{j}}\right)$.

(16) illustrerer imidlertid, at reference til type-ordet, N1, ikke virker så naturligt, mens reference til N2 fungerer helt fint. Dette kunne tolkes i retning af, at der er sket et skift i prominensforholdet mellem N1 og N2, således at $\mathrm{N} 1$ er blevet degraderet fra et leksikalsk til et grammatisk element, der i højere grad er "usynligt" i diskursen, jf. den indledende diskussion af grammatikalisering.

\subsubsection{Kongruens $i$ konstruktioner med 'slags'}

Ifølge DDO kan ordet slags både optræde som utrum og neutrum. Slags var oprindeligt en beskrivende genitiv af 'slag' med betydningen 'art' eller 'sort', som betegner "en kategori af genstande, individer eller fænomener der har bestemte kendetegn eller egenskaber tilfælles - også om beskrivelsen af en enkelt, typisk repræsentant for en sådan gruppe" (ordnet. $\mathrm{dk} / \mathrm{ddo} /$ ordbog? query=slags). Ordet kommer etymologisk set fra det tyske 'slages'/'schlages' (Nielsen 2004: 388). På baggrund af søgninger i ordbogsbasen på Renaessancesprog.dk er der grund til at antage, at ordet tidligere alene har været et neutrumssubstantiv, ligesom slag er det. I løbet af historien må slags derfor have skiftet køn.

$\mathrm{Vi}$ vil argumentere for, at slags ikke er blevet tvekønnet, som det hævdes i DDO, men at det i moderne dansk er entydigt utrum, når det optræder som substantiv. Forekomster, hvor det tilsyneladende optræder i neutrum, er $\mathrm{i}$ virkeligheden forekomster af en grammatikaliseret variant af slags $\mathrm{i}$ type-konstruktioner. Vores argument for dette er, at slags kan forekomme med en ubestemt artikel i enten utrum eller neutrum, når det forekommer med et $\mathrm{N} 2$ i neutrum (17), men kun med en artikel i utrum, når det forekommer med et N2 i utrum (18).

(17a) De bygger en helt ny slags hus.

(17b) De bygger et helt nyt slags hus. 
(18a) Hun har en helt ny slags cykel.

(18b) *Hun har et helt nyt slags cykel.

Jf. også, at slags kun kan optræde i utrum, når det ikke indgår i en typekonstruktion.

(19a) Hun har en cykel af en slags / et hus af en slags.

(19b) *Hun har et hus af et slags.

Disse påstande understøttes af korpusundersøgelsen: Der findes 1487 eksempler på konstruktionen EN/ET-slags-S, hvor S (N2) er et utrumssubstantiv. Ud af disse 1487 eksempler optræder kun to med neutrumsartiklen et foran slags. Til sammenligning er der i korpusset 1459 eksempler, hvor S (N2) er et neutrumssubstantiv. I $86 \%$ af disse eksempler forekommer slags med utrumsartiklen en, mens neutrumsartiklen optræder i 14\% af eksemplerne.

Det kan således konkluderes, at slags i praksis ikke er tvekønnet. Man kan antage, at korpusfundene afspejler, at N2 i 14\% af tilfældene med neutrums$\mathrm{S}$ har vundet kampen om diskursprominens over N1. Vi kan selvfølgelig ikke på baggrund af kongruens sige noget om styring og prominens i de 1487 eksempler, hvor N2 er et utrumssubstantiv.

Korpusundersøgelsen peger i øvrigt på, at hverken afstanden mellem artiklen og slags eller afstanden mellem slags og N2 synes at have indflydelse på kongruensen.

\subsection{Strukturel parallelisme}

Som analyserne undervejs har peget på, er der en strukturel analogi mellem på den ene side partitiver og det, vi her benævner fulde taksonomiske strukturer, og på den anden side pseudo-partitiver og type-konstruktioner. Mens de førstnævnte har en helt gængs kerne-attributiv-struktur, hvor attributivet har form af et præpositionssyntagme med et determineret nominal som styrelse, er det kort fortalt karakteristisk for pseudo-partitiver og type-konstruktioner, at N1 og N2 i stedet for at have status af separate syntaktiske elementer i et vist omfang smelter sammen til en enhed, hvor det er vanskeligt entydigt at afgøre, hvilket element der reelt fungerer som kerne i syntagmet. Typiske indikationer på denne fusion af N1 og N2 er, som vi har set, at modificerende adjektiver har skopus over hele enheden, at anaforisk reference og kongruensforhold bliver mere "flydende", og at der er bortfald af præpositionen med deraf følgende indskrænkninger ift. determination. Dette har medført, at man i litteraturen om specielt pseudo- 
partitiver taler om "head-switching", hvor N1 analyseres som specifikator eller klassifikator og N2 som kerne, eller om "split-headedness", hvor der skelnes mellem en syntaktisk, N1, og en semantisk kerne, N2, typisk i erkendelse af, at $\mathrm{N} 1$ er styrende for syntagmets præmodifikation i syntaktisk forstand (se fx Mihatsch 2016 og Müller 2016 blandt mange andre).

\section{Betydningen af slags (og andre type-ord)}

Den oprindelige, taksonomiske betydning af slags illustreres i (20), mens eksemplerne i henholdsvis (21) og (22) viser, hvordan slags kan være enten tvetydigt eller anvendes med en helt anden betydning end den taksonomiske.

(20) De var på ferie i Amsterdam og diskuterede livligt, hvad det var for en slags ænder, der svømmede rundt i kanalerne. (B1:1736)

(21) Vi er ikke i tvivl om, at bådene har fungeret som et slags lager for de etablerede hashhandlere på Christiania. (B1:144)

(22) Bush bliver en slags kransekagefigur i Det Hvide Hus. (B1:1924)

I (20) angiver slags klart en underkategori af ænder, hvorimod det i (22) ikke er muligt at forstå slags som markør for en underkategori. (21) er tvetydig, fordi man både kan argumentere for, at der faktisk er tale om en underkategori på linje med fjernlager eller fryselager, og samtidig, at det i stedet drejer sig om noget, der blot kan associeres med et lager.

Korpusundersøgelsen viser, at ud af 2946 eksempler med slags har 12\% en ren taksonomisk betydning, 33\% er tvetydige, og 55\% har en betydning forskellig fra den taksonomiske, som vi vil kalde associativ. Der er gode argumenter for, at denne associative betydningsvariant er diskursivt sekundær i Boye \& Harder's (2012) forstand. Den er stærkt associeret med den grammatikaliserede variant af slags, der blev omtalt i afsnit 2.2.6 - den variant, der ikke kan styre genus i sin artikel: Hele 92\% af eksemplerne, hvor slags ledsages af neutrumsartikel og neutrums-N2, er enten associative (60\%) eller tvetydige (32\%), og i et eksempel som (23) fremgår det tydeligt, at slags er diskursivt sekundært.

(23) Samarbejdet mellem forfatter og oversætter betragtes af mange som et slags kærlighedsforhold, hvor de mindste detaljer kan vendes og drejes i det uendelige (...) (B1:25) 
Opmærksomheden i ytringen i (23) retter sig mod at beskrive det pågældende samarbejde som noget, der kan associeres med et kærlighedsforhold, og ikke mod en eller anden form for underopdeling af kærlighedsforhold.

Det spiller en afgørende rolle for betydningen af slags, om der er afstand mellem artiklen og slags og mellem slags og N2. I første tilfælde, se (24), bruges slags langt overvejende i sin oprindelige taksonomiske betydning (86\% ud af 334 eksempler): De ord, såsom ny, anden, bestemt etc., der kan stå på pladsen mellem artiklen og slags, indikerer en kontrast til N2 i den forstand, at fx det nye forudsætter det gamle, det andet det første osv. I andet tilfælde forholder det sig modsat, jf. (25). 96\% af de 601 eksempler, hvor der er afstand mellem slags og N2-substantivet, har en tvetydig (24\%) eller en associativ $(72 \%)$ betydning. Dette skyldes formentlig, at man via modifikation af N2 fjerner sig fra substantivets grundbetydning og dermed en meningsfuld underopdeling af det af substantivet denoterede fænomen.

(24) De skrev med en anden slags bogstaver, som kaldes runer, og deres alfabet bliver kaldt Futhark. (B1:894)

(25) Lange romaner keder mig tit, så min form er måske en slags ubevidst oprør mod dem. (B1:2)

Generelt kan vi slå fast, at selv om den oprindelige betydning af slags ikke er forsvundet, er der sket en udvidelse af dette type-ords betydningsfelt, således at det i dag i overvejende grad bruges i tvetydige eller associative betydninger.

Hvad angår de øvrige type-ord art, form for og type, viser korpusundersøgelsen, der bygger på 150 eksempler med hvert ord, at der i forbindelse med art og form for kan spores de samme tendenser vedr. betydningsændring, som det var tilfældet for slags. Men type skiller sig ud fra de andre type-ord ved ikke at have gennemgået en betydningsændring (se også Denison 2005 for engelsk).

\section{Grammatikalisering}

Rutkowsky (2007) foreslår, at pseudo-partitiver dukker op i sprog som et resultat af en grammatikalisering af partitiver. I overensstemmelse hermed kan vi forstå type-konstruktioner som resultatet af en grammatikalisering af fulde taksonomiske binominaler: Både pseudo-partitiver og type-konstruktioner repræsenterer enklere funktionelle projektioner, som generelt betragtes som mere økonomiske og dermed mere grammatikaliserede end 
de leksikalske (Roberts \& Roussou 1999), hvor Nl's leksikalske status over tid er blevet erstattet af en grammatisk (Roberts \& Roussou 2003, Boye \& Harder 2012).

Der er altså tale om grammatikalisering på konstruktionsniveau, men denne konstruktionsgrammatikalisering ledsages i nogle tilfælde af en ordgrammatikalisering. Slags er et illustrativt eksempel på sådan en ordgrammatikalisering. Udgangspunktet for grammatikaliseringen er slags som leksikalsk ord, som utrumssubstantiv. Som utrumssubstantiv styrer det utrum i foranstillede artikler, uanset om det forekommer i et taksonomisk binominal eller ej, og uanset om et evt. ledsagende N2 er utrum eller neutrum. Grammatikaliseringen betinges af, at slags optræder i en binominal konstruktion, hvori det som N1 kan konkurrere med et N2 om diskursprominens. Grammatikaliseringen består i overensstemmelse med Boye \& Harder (2012) i en udvikling, hvori slags taber denne konkurrence så hyppigt, at der konventionaliseres en ny, grammatisk variant af ordet. Denne variant har fire egenskaber (jf. afsnit 2.2.6 om den første og afsnit 3 om den anden og tredje): 1) Den har mistet sin leksikalske status og dermed evnen til at styre genus i en foranstående artikel. Når den således som N1 ledsages af et N2, styres en evt. foranstående artikels genus af N2. 2) Den er diskursivt sekundær. 3) Den har associativ betydning. 4) Den er ikke som den leksikalske variant begrænset til konstruktioner, hvor N2 betegner en kategori, der lader sig underinddele. Mørchs korpusundersøgelse viser, at der på det nuværende sprogtrin er tale om såkaldt "layering": Den leksikalske og den grammatiske variant af slags sameksisterer.

På baggrund af Mørchs korpusundersøgelse er det rimeligt at forvente, at den grammatiske variant af slags gradvis vil vinde terræn. På nuværende tidspunkt tegner den sig kun for ca. 14\% af forekomsterne: Kun i 14\% af de tilfælde, hvor slags ledsages af et neutrumssubstantiv som N2, har det en neutrumsartikel (som altså vidner om, at slags har mistet sin substantiviske evne til at styre genus; jf. afsnit 2.2.6). Derimod er hele 55\% af de forekomster af slags, der er analyseret i Mørchs korpusundersøgelse, entydigt associative (jf. afsnit 3). Udviklingen af den associative betydningsvariant er altså langt mere fremskreden end udviklingen af et egentligt grammatisk tegn, men det er rimeligt at antage, at den semantiske udvikling driver den grammatiske: Den diskursivt sekundære associative betydningsvariant uddestilleres gradvis i en separat tegnvariant.

De øvrige type-ord - type undtaget - synes at følge en lignende udvikling, om end de ikke befinder sig på samme stade som slags. 


\section{Konklusion}

Vi har i denne artikel vist, at der er rimelige grunde til at antage, at pseudopartitiver og type-konstruktioner har undergået strukturelt set analoge grammatikaliseringsprocesser, idet de begge kan betragtes som syntaktisk forenklede versioner af henholdsvis partitiver og fulde taksonomiske strukturer.

Med udgangspunkt i Mørchs korpusundersøgelse af slags og andre type-ord i dansk samt Boye \& Harders (2012) grammatikaliseringsteori har vi også vist, at de strukturelle forandringer, herunder ikke mindst de i undersøgelsen behandlede kongruensmønstre, hænger nøje sammen med betydningsændringer og ordgrammatikalisering. På den baggrund mener vi at have tilvejebragt en god indsigt i det kompleks af faktorer, der fører til, at visse sproglige elementer over tid helt eller delvist mister deres fulde leksikalske status for at udvikle sig til diskursivt sekundære, grammatiske markører, der ultimativt har til formål, systematisk og generaliseret, at orientere de primære leksikalske elementers betydning i en bestemt retning.

\section{Om forfatterne}

Henrik Høeg Müller, ph.d., dr.ling.merc., Institut for Kommunikation og Kultur, Aarhus Universitet.

Kasper Boye, ph.d., Institut for Nordiske Studier og Sprogvidenskab, Københavns Universitet.

Elisabeth Agerbo Mørch, cand.mag. i lingvistik fra Institut for Nordiske Studier og Sprogvidenskab, Københavns Universitet.

\section{Litteratur}

Boye, K. \& P. Harder (2009): Hvad kvalificerer et leksikalsk element til grammatikalisering? I: Ny forskning i grammatik 16. L.F. Jakobsen, H. Jansen, E.S. Jensen \& E. Strudsholm (red.). Odense: Syddansk Universitet, 65-76.

Boye, K. \& P. Harder (2012): A usage-based theory of grammatical status and grammaticalization, Language 88(1), 1-44.

Boye, K. \& P. Harder (2014): (Inter)subjectification in a functional theory of grammaticalization, Acta Linguistica Hafniensia 46(1), 7-24.

Brems, L. (2003): Measure noun constructions: An instance of semantically driven grammaticalization. International fournal of Corpus Linguistics 8(2), 283-312.

Climent, S. (2001): Individuation by partitive constructions in Spanish. I: 
The language of Word Meaning. P. Bouillon \& F. Busa (red.). Cambridge: Cambridge University Press, 192-215.

Daugaard, J. (1994): Mængdehelheder. I: Nordlex-Projektet, Sammensatte substantiver i dansk. I. Baron (red.). Handelshøjskolen i København: Institut for Datalingvistik, 39-56.

Den Danske Ordbog (DDO): ordnet.dk/ddo.

Denison, D. (2005): The Grammaticalisations of Sort of, Kind of and Type of in English. I: New Reflections on Grammaticalisation (NRG) 3. University of Santiago de Compostela.

Keizer, E. (2007): The English Noun Phrase. The Nature of Linguistic Categorization. Cambridge: Cambridge University Press.

Koptjevskaja-Tamm, M. (2001). "A piece of the cake" and "a cup of tea": Partitive and pseudo-partitive nominal constructions in the Circum-Baltic languages. I: The Circum-Baltic Languages: Typology and Contact 2. Ö. Dahl \& M. Koptjevskaja-Tamm (red.). Amsterdam: Benjamins, 523-568.

Kopjevskaja-Tamm, M. (2006): Partitives. I: Encyclopedia of Languages and Linguistics 9. Keith Brown 2nd edition (red.). Amsterdam: Elsevier, 218-221.

Koptjevskaja-Tamm, M. (2009): A lot of grammar with a good portion of lexicon: towards a typology of partitive and pseudopartitive nominal constructions. I: Form and Function in Language Research. Papers in Honour of Christian Lehmann. J. Helmbrecht, Y. Nishina, Y.-M. Shin, S. Skopeteas \& E. Verhoeven (red.). Berlin / New York: Mouton de Gruyter, 329-346. Nielsen, N. Aa. (2004): Dansk etymologisk ordbog: ordenes historie, 5. udgave, København: Gyldendal.

Luraghi, S. \& T. Huumo (2014): Introduction. I: Empirical Approaches to Language Typology [EALT] 54: Partitive Cases and Related Categories. S. Luraghi \& T. Huumo (red.). München, DEU: Walter de Gruyter, 1-13.

Masini, F. (2016): Binominal constructions in Italian of the N1-di-N2 type: towards a typology of Light Noun Constructions. Language Science 53, 99-113.

Mihatsch, W. (2016): Type-noun binominals in four Romance languages. I: Binominal syntagms as a neglected locus of synchronic variation and diachronic change: towards a unified approach. L. Brems, B. De Clerch \& K. Verveckken (red.), 136-159.

Mirto, I.M. \& H. Necker (2007): Complex Nominal Determiners. A Contrastive Study. I: Europe and the Mediterranean as Linguistic Areas: Convergencies from a historical and typological perspective. P. Ramat \& E. Roma (red.). Amsterdam: John Benjamins, 215-243.

Müller, H.H. (2016): Metaphorical construction in Spanish pseudo-partitives 
and PP-adverbials. I: À la recherche de la prédication. Autour des syntagmes prépositionnels. C. Marque-Pucheu, F. Kakoyianni-Doa, P.A. Machonis \& H. Ulland (red.). Amsterdam/Philadelphia: John Benjamins, 89-104.

Mørch, E.A. (2017): 'Slags' og andre type-ord i dansk. Kandidatspeciale. Københavns Universitet, NorS.

Roberts, I. \& A. Roussou (1999): A formal approach to 'grammaticalization'. Linguistics 37, 1011-1041.

Roberts, I. \& A. Roussou (2003): Syntactic change: A minimalist approach to grammaticalization. Cambridge: Cambridge University Press.

Rutkowski, P. (2007): The Syntactic Structure of Grammaticalized Partitives (Pseudo-partitives). I: Proceedings of the 30th Annual Penn Linguistics Colloquium. University of Pennsylvania Working Papers in Linguistics 13, 337-350.

Stickney, H. (2007): From pseudopartitive to partitive. I: Proceedings of the 2nd Conference on Generative Approaches to Language Acquisition North America (GALANA). A. Belikova et al. (red.). Somerville, MA: Cascadilla Proceedings Project, 406-415. 